\title{
Belief and Deterministic Randomness in a One-Sector Discrete Time Optimal Growth Model : The Case of Hong-Kong
}

\author{
C-Rene Dominique ${ }^{*}$
}

\begin{abstract}
It is now well established that fears or arbitrary beliefs may become self-fulfilling economic prophecies. Given the oscillatory behavior displayed by the Hong-Kong economy since 1985, a constraining exogenous belief is modelled into a one-sector discrete time optimal growth model, which purports to mimic capital accumulation there. It shows that revisions of agents expectations, stemming from that belief, suffice to change the nature of the equilibrium point from fixed points to limit cycles of every integer period. In fact, as the real or imaginary but credible constraint is being approached, the economic system begins to display totally aperiodic trajectories which are indistinguishable from the realization of a stochastic process.
\end{abstract}

\section{Introduction}

During the decade preceeding 1985, the Hong-Kong economy grew in nominal terms at a yearly average rate of over $40 \%$. This extraordinary performance came to an abrupt stop in 1985, and is fluctuating since ${ }^{1}$. More specifically, in real terms, the rate of growth of the Gross Domestic Product in 1985 was zero. In 1986, investment outlays rose by some $7 \%$, exports by $16 \%$, the rate of unemployment declined by about $1 / 3$ to $2.2 \%$. The inflation rate rose somewhat, but GDP grew at $11.1 \%$. In 1987, private consumption jumped $16 \%$, fixed investments by $30 \%$, exports by $37 \%$, the unemployment rate fell to $1.8 \%$, GDP grew by $13.6 \%$. In early 1988 , only a $6 \%$ rate of growth was forecasted, but there has been in the meantime a feverish attempt by people and capital to

* Laval University

1. Data are from : The Far East and Australia, 1989, 2nd ed., Europa Pub. Ltd. London, 1989. 
emigrate. In 1989, mostly after the political events in China, there is a legitimate fear that the economy might go into a tailspin.

Clearly, these ups and downs in economic performance cannot be explained solely by the Government's monetary policy. It should be recalled that in 1985, the Hong-Kong dollar was officially linked to U.S. dollar. It was then argued in some quarters that the zero growth rate in 1985 was due to a loss of price competitiveness of Hong-Kong's goods in non US markets as the exchange rates of both currencies rose to high levels. However, 1985 was also the year when the Agreement (between the UK and China) to return the whole of Hong-Kong to China in 1997 was ratified. As one observes the obvious correlation between the approaching deadline, recent political developments in China and price movements in the H-K property market, the gigantic swings in the Hang Seng Index and the outward flow of people and investments, it seems more likely that the explanation has more to do with agents' expectations. Anyway, this is what will be argued below.

Indeed, there now exists an extensive literature on how revisions of agents' expectations, based on exogenous beliefs, can generate economic fluctuations (e.g. Shell, 1977 ; Cass and Shell, 1983, Azariadis and Guesnerie, 1986, among others). Further, and despite some counterclaims to that effect, it has been shown that such phenomena may occur in economies with capital accumulation and infinite lived agents (Guesnerie, 1986 : Woodford, 1986). However, here it is not a question of how expectations are formed nor of sunspot equilibria per se. The objective is much more modest. That is, suppose, after abstracting from the real world complexities, it is admitted that the growth path of the H-K economy is describable by a simple neoclassical discrete time optimal growth model $^{2}$. Then it suffices to introduce to that formulation a growth inhibitive factor, expressed in the form of an exogenous constraining belief, to surprisingly explain more realistically the observed violent swings in economic performance.

Such an approach is partly justified by the fact that difference equations are more appropriate tools for growth analyses, and partly due to the ease with which it can be demonstrated that the closer the economy gets to a given reckoning date, the more chaotic is its behavior. As it will be shown below, this last point is the crux of our thesis.

2. Of course such a formulation is predicated on a few additional assumptions, namely price and interest rate flexibility, linearly homogeneous technology, and full employment of resources. But the $\mathrm{H}-\mathrm{K}$ capital market is free and well developed, and in 1987, the unemployment rate of labor. was only $1.8 \%$. As there is no reason for not assuming a Cobb-Douglas tecnology, the necessary conditions seem to be met. 


\section{The Model}

Consider a typical neoclassical output market equilibrium equation (Samuelson, 1967 ; Takayama, 1985), modified for our purpose :

$$
\mathrm{K}_{(\mathrm{t}+1)}=\mathrm{F}\left(\mathrm{L}_{\mathrm{i}} \cdot \mathrm{K}_{\mathrm{t}}\right)+(1-\mathrm{d}) \mathrm{K}_{(\mathrm{t})}-\mathrm{C}_{(\mathrm{t})} .
$$

where $K_{(t+1)}$ is the stock of capital available for production in period $(t+1)$; $\mathrm{C}_{(\mathrm{t})}$ is consumption at $\mathrm{t} ; \mathrm{F}($.) is gross national output ; and $0<\mathrm{d}<1$ is the depreciation rate of the stock of capital, occurring at the end of the period. In addition, assuming Kuznets' behavior as regards the propensity to consume and a constant growth rate $(g \geq 0)$ for labor, the growth problem in (1) reduces to :

$$
\mathrm{k}_{(\mathrm{t}+1)}=(1+\mathrm{g})^{-1}\left[\mathrm{sB} \mathrm{k} \mathrm{k}_{\mathrm{t}}^{\beta}+(1-\mathrm{d}) \mathrm{k}_{\mathrm{t}}\right] \text {. }
$$

where $0\langle\mathrm{~s}\langle 1$ is the average propensity to save : $\beta\rangle 0$ is a technological constant ; $\mathrm{B}\rangle 0$ is the productivity multiplier : and $\mathrm{k}$ is the capital labor-ratio.

Albeit these simplifications, (2) is a discrete dynamical system defined on $\mathrm{R}_{+}^{2}$. Let $E$ be the vector field and $W$ an open subset of "states". Then (2) is a $C^{(1)}$ map $f: W \Rightarrow E$, producing a discrete family of states $n$ units of time later, denoted by $\left\{f^{n}(k) \mid n \in R+\right\}$, and converging to :

$$
\mathrm{k}^{*}=[\mathrm{sB} /(\mathrm{g}+\mathrm{d})]^{1 /(1-\beta)}
$$

It is quite obvious that every neighborhood $\mathrm{U} \subset \mathrm{W}$ of $\mathrm{k}^{*}$ contains a neighborhood $\mathrm{U}_{\mathrm{v}}$ of $\mathrm{k}^{*}$ such that $\mathrm{f}^{\mathrm{n}}\left(\mathrm{U}_{\mathrm{v}}\right) \subset \mathrm{U}$ for $\mathrm{n} \geq 0$, and $\lim \mathrm{f}^{\mathrm{n}}(\mathrm{k})=\mathrm{k}^{*}$ as $\mathrm{n} \Rightarrow \infty$ for all $\mathrm{k} \in \mathrm{U}_{\mathrm{v}}$. Then $\mathrm{k}^{*}$ is an asymptotically stable fixed point that for ease of exposition is here denoted a fixed point of period $2^{\circ}$. Consequently, investment cycles will never be observed in a system such as (2).

Introduce now a "belief" in (2), which could in essence derive from agents' expectation of the eventual end of the good life. In the present context, it could be a shared belief that capital accumulation is bounded from above at some $\bar{k}$. The introduction of such an upper bound would immediately compress the integral curves of (2), leading to dynamical behaviors which in no way resemble those of the initial system. Moreover, 
the closer the system gets to the upper bound, the more chaotic are its dynamics. To wit :

$$
\mathrm{k}_{\mathrm{t}+1)}=(1+\mathrm{g})^{-1}\left[\mathrm{sB} \mathrm{k} \mathrm{k}_{\mathrm{t}}^{\mathrm{p}}+(1-\mathrm{d}) \mathrm{k}_{\mathrm{t}}\right]\left(\overline{\mathrm{k}}-\mathrm{k}_{\mathrm{t}}\right)^{\gamma} / \mathrm{m} \text {. }
$$

to which we impose the restrictions $\gamma>0$, and $m>1$ : both are constant. $f($.$) is now uni-$ modal and it satisfies the usual conditions for an interior maximum. Consequently, the theorems of the unidimensional quadratic map become applicable.

\section{Analysis}

Denote $f^{\prime}($.$) as d\left(k_{(t+1)}\right) / d\left(k_{(t)}\right)$. Then for $\left.k_{t}\right) \max$, we have :

$$
\begin{aligned}
\mathrm{f}(\mathrm{s}) & =[\mathrm{m}(1+\mathrm{g})]^{-1}\left(\overline{\mathrm{k}}-\mathrm{k}_{\mathrm{t}}\right)^{\gamma}\left\{\left[\mathrm{sB} \beta / \mathrm{k}_{\mathrm{t}}^{1-\beta}+(1-\mathrm{d})\right]\right. \\
& \left.-\left[\mathrm{sB} / \mathrm{k}_{\mathrm{t}}^{1-\beta}+(1-\mathrm{d})\right] \gamma \mathrm{k}_{\mathrm{t}}\left(\overline{\mathrm{k}}-\mathrm{k}_{\mathrm{t}}\right)^{-1}\right\}=0
\end{aligned}
$$

As it was expected, $\mathrm{k}_{\mathrm{t}}$ ) max cannot be solved for explicitly, but numerical simulations show that for reasonable empirical values of $\mathrm{s}, \mathrm{B}, \beta, \mathrm{d}$, and in the range of $\mathrm{k}_{\mathrm{t}}$ applicable to the Hong-Kong economy, the ratio :

$$
\left[\mathrm{sB} \beta / \mathrm{k}_{\mathrm{t}}^{1-\beta}+(1-\mathrm{d})\right]\left[\mathrm{sB} / \mathrm{k}_{\mathrm{t}}^{1-\beta}+(1-\mathrm{d})\right]^{-1}
$$

is sensitive only to the value of and varies inversely with $B$. Let us call it $\theta$ (B). Upon substitution back into (5), we obtain :

$$
\left.\mathrm{k}_{\mathrm{t}}\right) \max =\theta(\mathrm{B}) \overline{\mathrm{k}} /(\gamma+\theta(\mathrm{B}))
$$

It can then be concluded that the graph of $f($.$\left.) peaks at k_{t}\right)$ max, and since $\theta(B)<1$, the higher is $\mathrm{B}$ the farther is $\mathrm{k}$ ) $\mathrm{t}$ max from $\overline{\mathrm{k}}$.

The nature of the critical point $\mathrm{k}^{*}$ can now be broadly characterized as follows : First, insert (6) into (4) to obtain the particular ratio :

$$
(\overline{\mathrm{k}} \gamma)^{\gamma}[\overline{\mathrm{k}} \theta(.)]^{\beta}\left[\mathrm{sB}+(1-\mathrm{d})(\theta(.) \overline{\mathrm{k}} / \theta(.)+\gamma)^{1-\beta}\right] / \mathrm{m}(1+\mathrm{g})(\theta(.)+\gamma)^{++\beta}
$$

denoted $\psi(\mathrm{s}, \mathrm{B}, \gamma, \mathrm{g})$ to indicate that it is sensitive to these parameters. Then if $\left.\psi(.) \leq \mathrm{k}_{\mathrm{t}}\right) \mathrm{max}$, capital accumulation converges monotonically to a fixed point like (3); if $\left.\psi()>.\mathrm{k}_{\mathrm{t}}\right) \max$, the system displays limit cycles of period $2^{r}(\mathrm{r}=1,2 \cdots, \mathrm{n})$; and as $\dot{\psi}($.) comes close to $\overline{\mathrm{k}}$, its behavior tends to become chaotic.

3. In terms of an analogy, the reader may picture a situation where someone would cry out : "police" at the door of the premise where an underground gambling operation is in progress. Clearly, the shorter the distance between police and gamblers, the more chaotic is the ensuing atmosphere on the premise. 
Considering the importance of this, let us look at it in another way. From (4), it can be seen that in equilibrium $\mathrm{k}^{*}(\mathrm{t}+1)=\mathrm{k}^{*}(\mathrm{t})$. This implies that :

$$
\left(\overline{\mathrm{k}}-\mathrm{k}_{\mathrm{t}}\right)^{\gamma}\left[\mathrm{sB} / \mathrm{k}_{\mathrm{t}}^{1-\beta}+(1-\mathrm{d})\right][\mathrm{m}(1+\mathrm{g})]^{-1} \equiv 1 .
$$

Upon substitution in (5), the slope equation simplifies to :

$$
\mathrm{f}^{\prime}\left(\mathrm{k}^{*} ; \cdots\right)=\left\{\theta(\mathrm{B})-\gamma \mathrm{k}^{*} /\left(\overline{\mathrm{k}}-\mathrm{k}^{*}\right)\right\},\left(\overline{\mathrm{k}}-\mathrm{k}^{*}\right) \neq 0 ;
$$

hence :

$$
f^{\prime}(.)\left\{\begin{array}{l}
>0 \\
=0 \\
\Rightarrow 0
\end{array}\right\} \text { whenever } k^{*}\left\{\begin{array}{c}
\langle k)_{\max } \\
=k) \max \\
>k)_{\max } \\
\Rightarrow \bar{k}
\end{array}\right\}
$$

But $\beta$ and $\mathrm{d}$ are more properly seen as technological constants that are not likely to be affected by agents' expectations. On the other hand, $\mathrm{k}^{*}$ increases with increases in s, B and $\gamma$, and falls with increases in $\mathrm{m}$ and $\mathrm{g}$; while $\mathrm{f}^{\prime}($.) becomes increasingly negative with increases in $\mathrm{B}$ and $\gamma$ as well as with decreases in $\Delta \mathrm{k}$, or equivalently as $\mathrm{t} \Rightarrow \mathrm{T}$, where $\mathrm{T}$ is some reckoning date in the future.

In fact, it can easily be shown that for reasonable empirical values of $\mathrm{B}^{*}, \gamma^{*}, \mathrm{~s}^{*}$, $\mathrm{g}^{*}, \mathrm{~d}^{*}, \overline{\mathrm{k}}^{*}$ and $\mathrm{m}^{*}$ an equilibrium in the sense of (8) exists. Therefore, according to (9) : for $\mathrm{f}^{\prime}()>-1,. \mathrm{k}^{*}$ is a fixed point. At $\mathrm{f}^{\prime}()=$.-1.000 , the system bifurcates into a limit cycle of period 2 ; at $f^{\prime}()=$.-1.449 , it bifurcates again into a limit cycle of period $2^{2}$. The period doubling process continues with limit cycles of period $2^{3}, 2^{4}$, etc. at $f^{\prime}($.) $=-1.544$ and -1.565 , respectively, until convergence to a critical value of -1.571 . For $-1.571>\mathrm{f}^{\prime}(\mathrm{f})=-1.8284$, the system exhibits an infinite number of fixed points of different periodicities, and an infinite number of different periodic cycles. Finally, beyond $\mathrm{f}^{\prime}()=$.-1.8284 , there are cycles of every integer periods and an infinite number of totally aperiodic cycles. In other words, in this region, the behavior of the system becomes indistinguishable from the realization of a stochastic process. From Li and Yorke's (1975) theorem, this situation can rightfully be termed chaotic.

What are then the main insights that emerge from this simple representation? Observe first how sensitive it is to revisions in agents' expectations. That is, how easily the saving rate can be revised ; how quickly the factor B can change due to the nature of contracts and as agents rush to complete them, or how quickly g can change as a result of massive emigration. In fact, even if nothing else happens, a rise in $\mathrm{B}$ alone or a fall in $\mathrm{g}$ alone would bring a rise in $\mathrm{k}^{*}$ and hence a more chaotic behavior. The next im- 
portant insight is that whether the limit $\overline{\mathrm{k}}$ (or $\mathrm{T}$ ) is real or imaginary, it only suffices that it is credible for these exotic phenomena to occur. Finally, given the present situation in Hong-Kong, none of these actions seem farfetched.

\section{Concluding Remarks}

During the 10 year period preceeding 1985, the performance of Hong-Kong's economy has been truly startling. However, since the Agreement to return the whole of Hong-Kong to China was ratified in May 1985, economic performance began to display an oscillatory behavior. Yet, under the Agreement, Hong-Kong is supposed to be constituted as a special administrative region, governed by its own inhabitants, in accordance with its own laws (except for diplomacy and defense) for 50 years beyond July 1 , 1997 (the date of transfer). What then explains the present convulsion? It is here argued that this is due to a belief which is causing agents to revise their expectations.

This was incorporated into a simple one sector optimal growth model in which the flow of time is discrete. It was then shown to be capable of quickly and radically modifying the integral curves of the phase portrait of the economy, leading to dynamical behaviors which may become outright chaotic, as long as the belief is held.

This then unambiguously suggests that either greater confidence on the part of the people of Hong-Kong in their future, and /or policy revisions in London and Beijing, not to mention certain guaranties, may go a long way in restoring economic stability in Hong-Kong.

\section{References}

Azariadis, C. and Guesnerie, R. (1986), "Sunspots and Cycles", Review of Economic Studies, vol. LIII, pp. 725-737.

Cass, D. and Shell K. (1983), "Do Sunspots Matter", Journal of Political Economy, vol. 91, pp. 193-227.

Europa Pub. Ltd. (1989), The Fast East and Australia, 1989, (20th ed.), London : Europa Pub. Ltd.

Guesnerie, R. (1986), "Stationary Sunspot Equilibria in an N-Commodity World", Nonlinear Economic Dynamics, edited by Grandmont, J.M., Academic Press, New York, pp. 103-127.

Li, T. and Yorke, J. (1975), "Period Three Implies Chaos", American Mathematical Mon- 
thly, vol. 82, pp. 985-992.

Samuelson, P.A. (1967), "A Turnpike Refutation of the Golden Rule in a Welfare Maximization Many Year Plan", Essays on the Theory of Optimal Economic Growth, edited by Shell, K., M.I.T. Press, Cambridge MA, p. 273.

Shell, K. (1977), "Money and Intertemporal Allocation”, mimeo, Centre National de la Recherche Scientifique, Paris.

Takayama, A. (1985), Mathematical Economics, (2nd ed.), New York : Cambridge Univ. Press.

Woodford, M. (1986), "Stationary Sunspot Equilibria in a Finance Constrained Economy”, Nonlinear Economic Dynamics, op. cit., pp. 128-147. 